\title{
Modeled climate change effects on distributions of Canadian butterfly species
}

\author{
A. Townsend Peterson, Enrique Martínez-Meyer, Constantino González-Salazar, \\ and Peter W. Hall
}

\begin{abstract}
Climate change effects on biodiversity are being documented now frequently in the form of changes in phenology and distributional shifts. However, the form that these effects will take over a longer timespan is unclear; for this understanding, a quantitative, validated, predictive approach is key. Here, we use ecological niche modeling and general circulation model outputs to estimate future potential geographic distributions of 111 Canadian butterfly species. We develop future estimates under two emission scenarios from each of two climate change modeling centers; future projections for biodiversity are not only scenario dependent (more severe emission scenarios produce more severe effects on species' distributions) but also model dependent (the Canadian Centre for Climate Modelling and Analysis results were more severe than the Hadley Centre results). One interesting feature is the appearance of disjunctions in species' distributions, hence creating "vicariant events" over very short time periods. In general, however, a cost of $1 \%-3 \%$ additional loss of species' distributions is associated with more severe scenarios of emissions and climate change, suggesting that subtle biodiversity consequences are associated with the different climate futures debated in political circles.
\end{abstract}

Résumé : La littérature scientifique courante traite fréquemment des effets des changements climatiques sur la biodiversité, particulièrement en ce qui a trait aux changements phénologiques et aux modifications des répartitions géographiques. Cependant, la forme que prendront ces effets sur une échelle temporelle plus longue reste à préciser, car pour ce faire il est nécessaire d'avoir recours à une approche quantitative, validée et prédictive. Les résultats d'une modélisation de la niche écologique et de modèles de circulation générale nous ont servi à estimer la répartition géographique potentielle future de 111 espèces de papillons canadiens. Nous avons basé nos prédictions sur deux scénarios d'émissions provenant de deux centres de modélisation du climat; ces prédictions de la biodiversité dépendent non seulement du scénario choisi (les scénarios d'émissions plus importantes produisent des effets plus marqués sur la répartition des espèces), mais aussi du modèle retenu (les résultats du Centre canadien pour la modélisation et l'analyse du climatique sont plus rigoureux que ceux du Centre Hadley). Une caractéristique intéressante est l'apparition de fragmentations dans la répartition des espèces, ce qui crée des «événements de vicariance » sur de très courtes périodes. En général, cependant, un coût de $1 \%-3 \%$ en perte additionnelle dans les répartitions accompagne les scénarios les plus rigoureux de changement climatique, ce qui indique que les conséquences sur la biodiversité des divers scénarios climatiques futurs discutés dans les milieux politiques sont assez subtiles.

[Traduit par la Rédaction]

\section{Introduction}

Climates worldwide have seen dramatic changes over the past several decades, including a broad overall warming trend as well as local and regional rearrangements and shifts in other aspects of climate (Karl et al. 1996; Magnuson 2001). These changes have already resulted in numerous effects on species' distributions and phenology (Parmesan 1996; Visser et al. 1998; Parmesan et al. 1999; Inouye et al. 2000; Walther et al. 2002), with general trends towards earlier spring activity, poleward colonization, and equator-side extinctions in species' distributions (Parmesan and Yohe 2003). Such climate change implications for biodiversity lead to obvious concern regarding effects on conservation status of many species (Peters and Darling 1985; Dobson et al. 1989; Peters and Myers 1991-1992; Chapin et al. 2000).

Anticipating climate change effects on biodiversity based on shifts already manifest, however, have the potential to fail in anticipating further effects in a changing climate. That is, how can we avoid "closing the barn door after the horse has gotten out" if we "anticipate" phenomena only once they have been observed? Thus, this situation calls for approaches

Received 22 July 2003. Accepted 21 May 2004. Published on the NRC Research Press Web site at http://cjz.nrc.ca on 30 July 2004.

A.T. Peterson. ${ }^{1}$ Natural History Museum and Biodiversity Research Center, University of Kansas, Lawrence, KS 66044 , USA.

E. Martínez-Meyer and C. González-Salazar. Instituto de Biología, Universidad Nacional Autónoma de México, México, D.F. 04510 México.

P. W. Hall. Director, Biodiversity Information Services, United Nations Environment Programme - World Conservation Monitoring Centre, Cambridge, UK.

${ }^{1}$ Corresponding author (e-mail: town@ku.edu). 
that have greater anticipatory potential, whereby extrapolation and prediction based on quantitatively validated models become key steps.

Great effort has been invested in modeling challenges aimed at anticipating both the physical effects of climate change and the biological implications of those effects. At the foundation of such efforts have been global models (general circulation models or GCMs) of future climates based on scenarios of future atmospheric composition (Flato et al. 1999; Pope et al. 2002), which have resulted in an integrated present and future climate data archive (Intergovernmental Panel on Climate Change 2001). Numerous studies have focused on the challenge of translating climate shifts into shifts in biomes and ecosystems (Emanuel et al. 1985; Prentice and Webb 1989; King and Leemans 1990; Prentice et al. 1992; Foley et al. 1996; Haxeltine and Prentice 1996; Melillo et al. 1996; Prentice and Webb 1998; Tian et al. 1998, 1999). Yet another series of analyses has focused on anticipating climate change effects on geographic distributions of individual species via ecological niche modeling (Carey and Brown 1994; Huntley et al. 1995; Kadmon and Heller 1998; Price 2000; Rutherford et al. 2000; Peterson et al. 2001, 2002b; Bakkenes et al. 2002; Erasmus et al. 2002; Peterson 2003; Siqueira and Peterson 2003). This latter approach is based on models of species' coarse-scale ecological niches, as known occurrence points of species are related to climate and other landscape features to produce a model of appropriate conditions for populations of the species; this ecological niche model can then be projected onto presentday climates to predict current distributional areas or onto modeled future climates to predict future potential distributional areas (Peterson et al. 2001).

This study presents predictions of climate change effects on the Canadian butterfly fauna. Butterflies in general represent an ideal group on which to focus regarding climate change effects, because their taxonomy is well understood, distributional information is relatively abundant and precise, and at the same time the species often have relatively small distributional areas and high sensitivity to climatic factors, making them sensitive to climate considerations. Although this fauna (and in fact the same data set) has been the subject of a previous quantitative geographic analysis (Kerr 2001), detail achieved in viewing species-richness patterns in that previous study was not great, and no direct assessment of climate change effects was made. Hence, we focus, for the first time, on comparisons of the relative implications of different scenarios and climate modeling efforts for species' distributions, comparing in detail two scenarios (conservative and liberal scenarios regarding greenhouse gases in the atmosphere) from each of two climate change modeling centers (Flato et al. 1999; Pope et al. 2002). These comparisons help to illustrate $(i)$ the degree to which climate change projections for species' distributions are scenario dependent, (ii) the degree to which different modeling centers' results produce different future projections for species, and (iii) the biodiversity consequences of different greenhouse gas emissions scenarios.

\section{Methods}

The general approach to ecological niche modeling of cli- mate change effects on biodiversity used herein is described in detail elsewhere (Peterson et al. 2001, 2002b) as are details of the algorithm used for modeling species' ecological niches (see detailed description below) (Stockwell and Noble 1992; Stockwell 1999; Stockwell and Peters 1999). Previous tests of the predictive ability of this modeling technique for diverse biodiversity phenomena in various regions have been published elsewhere (Peterson and Cohoon 1999; Peterson 2001; Peterson and Vieglais 2001; Peterson et al. 2002a, 2002c, 2002d; Stockwell and Peterson 2002a, 2002b; Anderson et al. 2003).

We obtained distributional data for all 297 butterfly species occurring in Canada from data sets assembled by P.W. Hall and colleagues. The data set includes specimen records of 297 Canadian butterfly species from 40 Canadian natural history collections dating back to the middle 1800 s and totals about 300000 records, each of which was verified and georeferenced by a knowledgeable lepidopterist. To avoid sample-size problems in development of models for species' geographic distributions (Stockwell and Peterson 2002b), we analyzed only the 111 species for which $\geq 30$ unique occurrence records were available (median number of unique occurrence records in the overall data set was 156). A total of 18403 unique latitude-longitude $\times$ species combinations were available for the target species.

Geographic information sytem data sets summarizing different ecological dimensions included 10 map layers summarizing aspects of topography (slope, aspect, flow direction, flow accumulation, and a measure of upward curvature and tendency to pool water; all of the data products available from the US Geological Survey 2000) and aspects of climate including precipitation, maximum, minimum, and mean temperatures, and solar radiation (annual means, 1961-1990; from the Intergovernmental Panel on Climate Change 2003). Climate dimensions analyzed included all annual mean characteristics for which both present and modeled future scenarios were available. The region analyzed extended 100-200 km south of the United States - Canada border to avoid any edge effects on model development.

We used GCM results from the Hadley (Pope et al. 2002) and Canadian (Flato et al. 1999) climate change modeling centers as the basis for our future climate projections. At difference from our previous analyses (Peterson et al. 2001, $2002 b$ ), however, we incorporated the "next generation" of climate change modeling results (HadCM3 and CGCM1, respectively). From each climate change modeling center, we assessed the same two scenarios: one conservative and one less conservative view of how climates could change over the next 50 years using the B2 and A2 emissions scenarios (Nakicenovic and Swart 2000), respectively. These scenarios are based on a 30-year average around 2055 (2040-2069), so our models do not take into account the potential effects of increased climate variability (El Niño events in particular) on species' distributions.

The two climate modeling centers present distinct implementations of simulations of climates under the same sets of assumptions regarding emissions of the so-called greenhouse gases and so may differ in their predictions. The different scenarions, however, depend on different future atmospheric compositions resulting from different assumptions regarding world development. The A2 scenario is described as "a very 
heterogeneous world. The underlying theme is that of strengthening regional cultural identities, with an emphasis on family values and local traditions, high population growth, and less concern for rapid economic development." This scenario, as implemented by various climate modeling centers, yields global increases in temperatures predicted for 2100 of $3.0-5.2^{\circ} \mathrm{C}$. The B2 scenario, on the other hand, is described as "a world in which the emphasis is on local solutions to economic, social, and environmental sustainability. It is again a heterogeneous world with less rapid, and more diverse technological change but a strong emphasis on community initiative and social innovation to find local, rather than global solutions." This scenario results in a range of $2.1-3.9{ }^{\circ} \mathrm{C}$ increases predicted by the simulations of the various climate modeling centers.

As GCM data are provided at crude spatial resolutions (Hadley, $2.5^{\circ} \times 3.75^{\circ}$; Canadian, $3.75^{\circ} \times 3.75^{\circ}$ ), we downscaled them by extracting expected changes in each dimension under each scenario and applying the expected positive or negative changes to the finer scale $\left(0.5^{\circ} \times 0.5^{\circ}\right.$ resolution $)$ Intergovernmental Panel on Climate Change current climate data layers; this resolution represents the finest downscaling possible using this approach (i.e., without development of a regional climate model) and meshes well with the sometimes less than precise georeferencing of the butterfly occurrence data.

The ecological niche of a species can be defined as the conjunction of ecological conditions within which it is able to maintain populations without immigration (Grinnell 1917); as such, it is defined in multidimensional ecologicalenvironmental space. At difference from later conceptualizations of the niche (MacArthur 1972), this niche concept provides a clear geographic focus, essential to the approach used herein. Several approaches have been used to approximate species' ecological niches (Austin et al. 1990; Walker and Cocks 1991; Carpenter et al. 1993); of these, a very robust option is the genetic algorithm for rule-set prediction (GARP), which includes several inferential approaches in an iterative machine-learning approach (Stockwell and Peters 1999). A recently developed flexible and user-friendly user interface is now available for download (Scachetti-Pereira 2002).

Available occurrence points are divided into data sets for model building ( $25 \%$ for model training and $25 \%$ for intrinsic testing and tuning of models) and extrinsic test data sets $(50 \%)$. GARP is designed to work based on presence-only data; absences are included in the modeling exercise via sampling of points from the set of pixels where the species has not been detected. This set of "pseudoabsence" points usually includes some actual presences (unsampled) but is useful, as its prior probability of presence is decidedly below unity. GARP works in an iterative process of rule selection, evaluation, testing, and incorporation or rejection: first, a method is chosen from a set of possibilities (e.g., logistic regression, bioclimatic rules) and then is applied to the training data and a rule developed; rules may evolve by a number of means (e.g., truncation, point changes, crossing-over among rules) to maximize predictivity. Predictive accuracy is then evaluated based on 1250 points resampled from the test data and 1250 points sampled randomly from the study region as a whole. The change in predictive accuracy from one itera- tion to the next is used to evaluate whether a particular rule should be incorporated into the model, and the algorithm runs either 1000 iterations or until convergence.

Projection of GARP models onto present landscapes provides an estimate of present-day geographic distribution of suitable conditions and allows tests of model predictivity. In general, the extrinsic test data are overlaid and observed correct predictions are tallied. Expected correct values if model and test points are randomly associated were calculated as the proportional area in the study area predicted present $\times$ number of extrinsic test data points. A $\chi^{2}$ approach $(1 \mathrm{df})$ is used to test the significance of the departure from random expectations. Because species' distributions are limited by combined effects of ecological and historical factors (e.g., barriers to dispersal) (MacArthur 1972), we inspected present-day predictions for each species to detect areas of overprediction; as these overpredictions turned out to be rare ( $\sim 3 \%$ of species), we made no correction to reduce predicted areas. Given the best-subsets approach, which filtered out models that omitted heavily, areas of underprediction of species' distributions were perforce rare.

Ecological niche models developed with GARP can be projected onto both current and modeled future landscapes. GARP models consist of an ordered series of if-then statements that predict either presence or absence; these statements can be applied to the transformed landscapes to identify areas of potential distribution for a species after the modeled sequences of environmental change (e.g., GCM results). We synthesized the prechange and four postchange maps (liberal and conservative scenarios for two modeling centers) for each species by measuring potential distributional area under an explicit assumption of no dispersal ability. Although suites of assumptions were considered in past applications (Peterson et al. 2001), we assumed that most butterfly species in Canada would be limited either by their own capacities for dispersal or by the dispersal capacities of their habitats (e.g., a particular forest type) or food plants. Hence, we used only the "no dispersal" assumption of past applications (i.e., species are unable to disperse and would inhabit only those portions of present distributional areas that remain habitable) (Peterson et al. 2001); however, this assumption is clearly not universally tenable (Parmesan et al. 1999). Operationally, modeled present distributions were reduced to those areas predicted to be habitable post change. Overall, these analyses assume no evolution in niche characteristics (Peterson et al. 1999) and do not take into account shifts in interactions among species such as competition, predation, etc.

\section{Results}

We first assessed the predictive ability of ecological niche models for each species in the present based on the half of the occurrence points that was set aside prior to model building. Models for all 111 species were highly statistically significant, with the vast majority significantly predictive above and beyond random expectations $(P<0.05$ for $99.8 \%$ of models, $P<10^{-5}$ for $96.8 \%$ of models). Moreover, the area predicted present in models was not related to numbers of occurrence points available for analysis $\left(R^{2}=0.07, P>\right.$ $0.05)$. 
Fig. 1. Two examples of future projections of the distributional potential of butterfly species' distributional potential in the face of global climate change. Top, Colias hecla Lefèbvre, 1836; bottom, Colias palaeno (L., 1761). Colored lines indicate predicted range limits under different scenarios of climate change: red, CGCM1-A2; pink, CGCM1-B2; green, HadCM3-A2; blue, HadCM3-B2. Points plotted are occurrences used to build models.

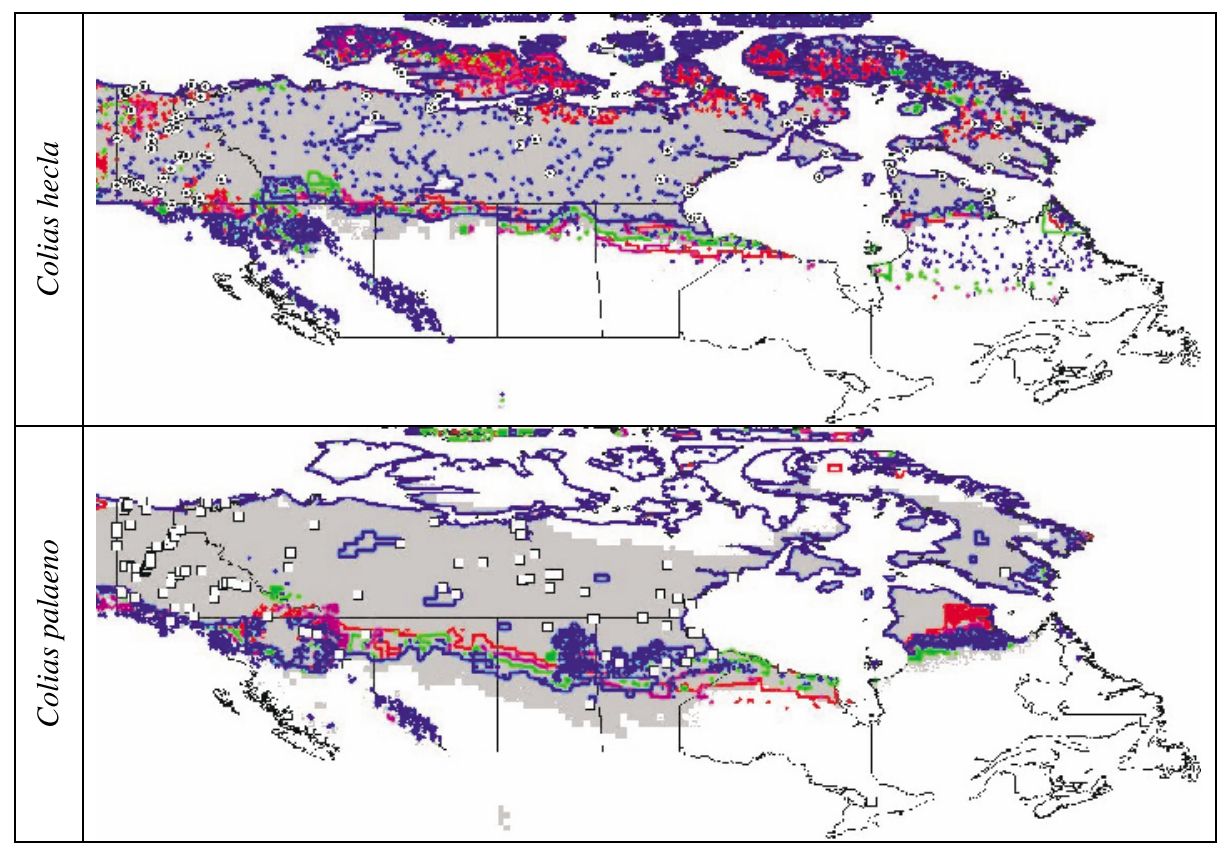

Projection of present-day ecological niche models to future climates revealed relatively subtle implications for species' distributions (e.g., Fig. 1). In general, species' distributions were projected to retract somewhat along the southern fringe, except in montane regions, such as the Rocky Mountains. (Frequently, areas to the north of present distributional areas were predicted to become habitable for species, but these effects were not considered further given our assumption of zero dispersal.) Across all 111 species analyzed, no dependence of severity of climate change effects (percentage of distributional area lost) on present distributional area was observed (four climate change scenarios averaged; $\left.R^{2}=0.02, P>0.05\right)$. In general, comparing species-richness patterns at present and in the future, a general northward shift is evident in butterfly distributions in Canada (Fig. 2); intriguing is the apparent reduction of diversity in the Toronto region, which is either a consequence of genuine species loss or could represent an artifact of not having included in this study species not presently occurring in Canada.

Comparing predicted effects on species' potential distributional areas among climate change scenarios and modeling centers revealed consistent differences (Fig. 3). CGCM1-A2 and CGCM1-B2 were, in general, more severe in their predictions of consequences for species' geographic distributions, with more species entering in the range of only $60 \%-$ $80 \%$ of distributional areas retained. HadCM3-A2 and HadCM3-B2, on the other hand, were generally less severe, with most species retaining $\geq 80 \%$ of their distributional areas (comparing average of two CGCM1 scenarios with average of two HadCM3 scenarios; paired $t$ test, $t_{[110]}=8.43$, two-tailed $P<10^{-12}$ ). Comparisons between the A2 and B2 scenarios (average of two A2 scenarios versus average of two B2 scenarios; paired $t$ test, $t_{[110]}=12.41$, two-tailed $P<$ $10^{-21}$ ) indicated that the A2 scenarios are more drastic for species' distributions.

\section{Discussion}

The analyses developed herein achieve much-improved spatial resolution in viewing current patterns of species richness than past studies (Kerr 2001) based on the same fauna and same data set. This improvement is possible via our relating relatively precise occurrence points to underlying patterns of variation in ecological parameters in the development of species-specific ecological niche models. Such models, and their projections back onto geography, make possible broad summary of biodiversity patterns without the loss of information that is inevitable when data are aggregated to cruder spatial scales (Stockwell and Peterson 2002a).

Projection of species' ecological needs to future climate scenarios provides a first view of the likely effects of climate change on species' geographic potential. In general, loss of distributional area is relatively subtle, with an average of $87.1 \%-93.3 \%$ of present distributional areas retained, depending on the particular scenario. The two species predicted to be most severely affected, Feniseca tarquinius (Fabricius, 1793) and Boloria polaris (Boisduval, 1828), are predicted to lose only $29 \%$ of their present distributional areas. In this respect, biodiversity implications of global climate change for Canada resemble those from Mexico (Peterson et al. 2002b) and the Rocky Mountains much more than those from the Great Plains of the central United States (Peterson 2003) or the cerrado of Brazil (Siqueira and Peterson 2003). This result seems a bit odd, given the contiguous 
Fig. 2. Geographic patterns of butterfly species richness at present and in 2055 based on the HadCM3-B2 scenario. Gradations from white (0 species) to black (100-103 species) are in intervals of 10 (e.g., 1-10, 11-20, etc.).

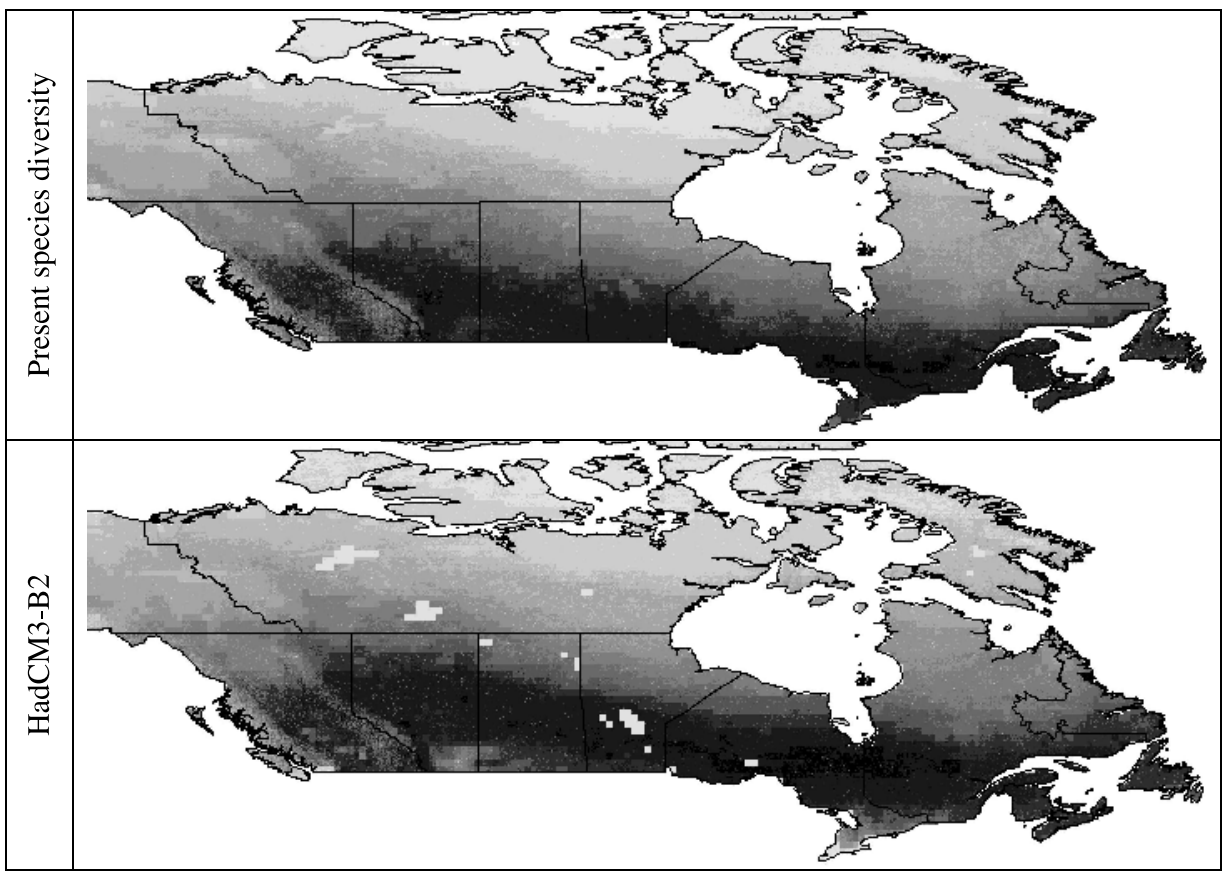

Fig. 3. Comparison of percentage of area retained by 111 species of Canadian butterflies under four scenarios of climate change. Note the generally more severe expectations of climate change implications under the Canadian climate change modeling center scenarios.

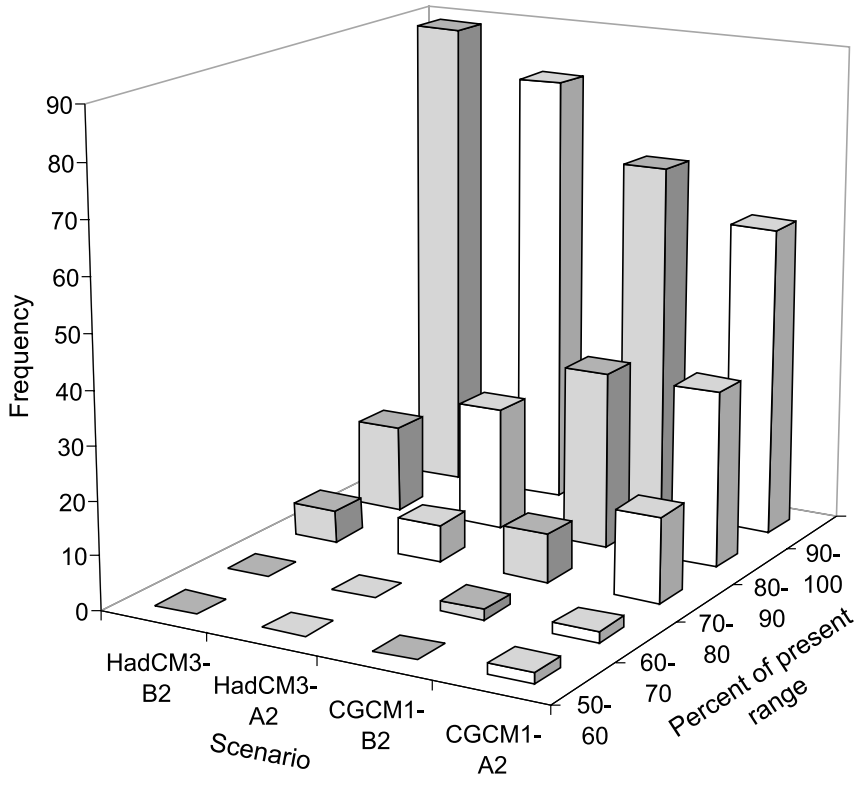

nature of the Great Plains with much of Canada and the general similarities of environment and land use patterns; a clear result, however, is that much more comparative work is necessary for generalization.

A very interesting phenomenon that was observed in some future predictions is a tendency towards production of vicariant events. For example, Oeneis polixenes (Fabr., 1775) presently is predicted to occur across central Canada, including the area immediately south of the southern tip of Hudson Bay; under future climates, however, its northward shift is sufficient enough that the populations east and west of Hudson Bay are predicted to be isolated from one another (Fig. 4). Another example is $F$. tarquinius, which is predicted to develop a disjunction in western Canada. These examples suggest that another effect of global climate change on biodiversity may be the creation of new barriers, effectively creating vicariant events.

Our results also serve to identify complexities of using ecological niche modeling to predict climate change effects on biodiversity. First, two major climate modeling centers produce GCMs that yield predictions which differ from one another; the Canadian climate change modeling group's projections are considerably more severe in their effects on species' distributions than are those of the Hadley Centre even when considered under the same emissions scenarios (87.10\% versus $92.02 \%$ of distribution retained for A2 and $90.46 \%$ versus $93.29 \%$ of distribution retained for B2 in CGCM1 and HadCM3, respectively). In this sense, projections of biodiversity phenomena to future climates should at a minimum consider the implications of a variety of GCM predictions rather than basing conclusions on just one.

Finally, as expected, the two future climate scenarios (A2 and B2) considered for each climate modeling center also differed in their implications for biodiversity phenomena. A2 scenarios had somewhat more serious implications for species' distributional reductions than B2 scenarios. These two scenarios map directly onto scenarios of world socioeconomic future and future emissions of greenhouse gases (Nakicenovic and Swart 2000), so the difference (1.27\%$3.36 \%$ ) in amount of present distribution retained (for Canadian butterflies) can be associated directly with differences in emissions and lifestyles. These additional losses of distributional area are the biodiversity consequences predicted if 
Fig. 4. Example of predicted vicariance as a consequence of global climate change: Oeneis polixenes. Present predicted distribution is in gray; future predicted distribution is in black (pictured on top of the present predicted distribution).

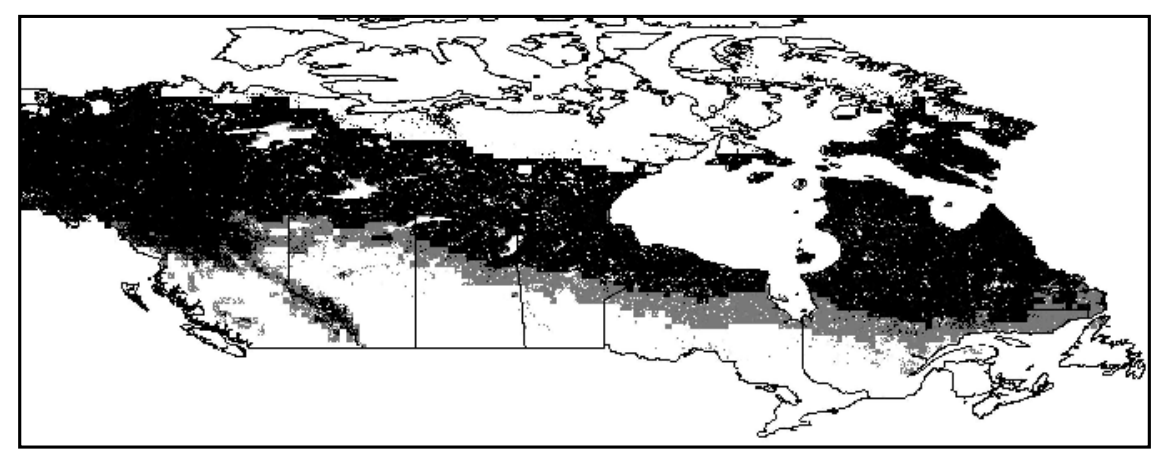

the future proves more similar to the drastic, rather than the conservative, scenario of climate change.

Several complications, however, should be kept in mind. First, for practical reasons of need for sufficient occurrences to train models, we focus on species of relatively broad distribution; these species may prove to be those that are most able to respond to changing conditions. Moreover, the biological reality of these climate change projections for Canadian butterfly species is complicated by the ability or inability to predict accurately the dispersal and butterfly usage, under the influence of climate change, of larval food plants. Several butterfly species are closely associated with their butterfly larval food plants. These plants, many of which are highly localized to specific climate, soil, associated vegetation, and other conditions, may not be able to migrate with the dispersing butterfly populations. These interaction effects are particularly important for those butterfly species with a single larval food plant. On the other hand, some butterfly species in known historical dispersal events have been able to transfer to related, but previously unrecorded, food plants. Many more butterfly species, however, are tightly tied to specific habitat types, and thus, will require coordinated movement of climatic conditions and vegetation to be able to track conditions spatially. Although some recent studies have documented nonzero dispersal abilities in butterflies (e.g., Parmesan 1996; Parmesan et al. 1999), the above considerations suggest that dispersal may not always be sufficient to permit tracking of appropriate conditions; detailed comparisons and analyses of effects of dispersal scenarios, and their interactions with climate change effects, would be a fruitful avenue for future investigation.

\section{Acknowledgments}

We thank Larry Speers of the Global Biodiversity Information Facility and the coauthors of "Butterflies of Canada" (Ross Layberry and Donald Lafontaine) for generously providing us with access to the Canadian butterflies data set. Thalia Tooke invested great amounts of time in early exploration of these ideas. This study was funded by the US National Science Foundation.

\section{References}

Anderson, R.P., Lew, D., and Peterson, A.T. 2003. Evaluating pre- dictive models of species' distributions: criteria for selecting optimal models. Ecol. Model. 162: 211-232.

Austin, M.P., Nicholls, A.O., and Margules, C.R. 1990. Measurement of the realized qualitative niche: environmental niches of five Eucalyptus species. Ecol. Monogr. 60: 161-177.

Bakkenes, M., Alkemade, J.R.M., Ihle, F., Leemansand, R., and Latour, J.B. 2002. Assessing effects of forecasted climate change on the diversity and distribution of European higher plants for 2050. Global Change Biol. 8: 390-407.

Carey, P.D., and Brown, N.J. 1994. The use of GIS to identify sites that will become suitable for a rare orchid, Himantoglossum hircinum L., in a future changed climate. Biodivers. Lett. 2: $117-123$.

Carpenter, G., Gillison, A.N., and Winter, J. 1993. DOMAIN: a flexible modeling procedure for mapping potential distributions of animals and plants. Biodivers. Conserv. 2: 667-680.

Chapin, F.S.I., Zavaleta, E.S., Eviner, V.T., Naylor, R.L., Vitousek, P.M., Reynolds, H.L., Hooper, D.U., Lavorel, S., Sala, O.E., Hobbie, S.E., Mack, M.C., and Diaz, S. 2000. Consequences of changing biodiversity. Nature (Lond.), 405: 234-242.

Dobson, A., Jolly, A., and Rubenstein, D. 1989. The greenhouse effect and biological diversity. Trends Ecol. Evol. 4: 64-68.

Emanuel, W.R., Shugart, H.H., and Stevenson, M.P. 1985. Climate change and the broad-scale distribution of terrestrial ecosystem complexes. Clim. Change, 7: 29-43.

Erasmus, B.F.N., Van Jaarsveld, A.S., Chown, S.L., Kshatriya, M., and Wessels, K.J. 2002. Vulnerability of South African animal taxa to climate change. Global Change Biol. 8: 679-693.

Flato, G.M., Boer, G.J., Lee, W.G., McFarlane, N.A., Ramsden, D., Reader, M.C., and Weaver, A.J. 1999. The Canadian Center for Climate Modelling and Analysis Global Coupled Model and its climate. Clim. Dyn. 16: 451-467.

Foley, J.A., Prentice, I.C., Ramankutty, N., Levis, S., Pollard, D., Sitch, S., and Haxeltine, A. 1996. An integrated biosphere model of land surface processes, terrestrial carbon balance and vegetation dynamics. Global Biogeochem. Cycles, 10: 603-628.

Grinnell, J. 1917. Field tests of theories concerning distributional control. Am. Nat. 51: 115-128.

Haxeltine, A., and Prentice, I.C. 1996. BIOME3: An equilibrium terrestrial biosphere model based on ecophysiological constraints, resource availability and competition among plant functional types. Global Biogeochem. Cycles, 10: 693-709.

Huntley, B., Berry, P.M., Cramer, W., and McDonald, A.P. 1995. Modelling present and potential future ranges of some European higher plants using climate response surfaces. J. Biogeogr. 22: 967-1001.

Inouye, D.W., Barr, B., Armitage, K.B., and Inouye, B.D. 2000. Climate change is affecting altitudinal migrants and hibernating species. Proc. Natl. Acad. Sci. U.S.A. 97: 1630-1633. 
Intergovernmental Panel on Climate Change. 2003. Climate data archive. Available from http://www.ipcc.ch/ [accessed 1 February 2003].

Kadmon, R., and Heller, J. 1998. Modelling faunal responses to climatic gradients with GIS: land snails as a case study. J. Biogeogr. 25: 527-539.

Karl, T.R., Knight, R.W., Easterling, D.R., and Quayle, R.G. 1996. Indices of climate change for the United States. Bull. Am. Meteorol. Soc. 77: 279-292.

Kerr, J.T. 2001. Butterfly species richness patterns in Canada: energy, heterogeneity, and the potential consequences of climate change. Conserv. Ecol. [online], 5: 10. Available from http:// www.consecol.org/vol15/iss11/art10 [cited 1 March 2003].

King, G.A., and Leemans, R. 1990. Effects of global climate change on global vegetation. In Response and feedback of forest systems to global climate change. Edited by G.A. King, J.K. Winjun, P.K. Dixon, and L.Y. Arnaut. Environmental Protection Agency, Corvallis, Oreg.

MacArthur, R. 1972. Geographical ecology. Princeton University Press, Princeton, N.J.

Magnuson, J. 2001. 150-year global ice record reveals major warming trend. Inter-Am. Inst. Global Change Res. 24: 22-25.

Melillo, J.M., Prentice, I.C., Farquhar, G.D., Schulze, E.-D., and Sala, O.E. 1996. Terrestrial biotic responses to environmental change and feedbacks to climate. In Climate change 1995: the science of climate change. Edited by J.T. Houghton, L.G. Meira Filho, B.A. Callander, N. Harris, A. Kattenberg, and K. Maskell. Cambridge University Press, Cambridge, UK. pp. 444-481.

Nakicenovic, N., and Swart, R. (Editors). 2000. Emissions scenarios: a special report of Working Group III of the Intergovernmental Panel on Climate Change. Cambridge University Press, Cambridge, UK.

Parmesan, C. 1996. Climate and species' range. Nature (Lond.), 382: $765-766$.

Parmesan, C., and Yohe, G. 2003. A globally coherent fingerprint of climate change impacts across natural systems. Nature (Lond.), 421: 37-42.

Parmesan, C., Ryrholm, N., Stefanescu, C., Hill, J.K., Thomas, C.D., Descimon, H., Huntley, B., Kaila, L., Kullberg, J., Tammaru, T., Tennent, J., Thomas, J.A., and Warren, M. 1999. Poleward shift of butterfly species' ranges associated with regional warming. Nature (Lond.), 399: 579-583.

Peters, R.L., and Darling, J.D.S. 1985. The greenhouse effect and nature reserves. Bioscience, 35: 707-717.

Peters, R.L., and Myers, J.P. 1991-1992. Preserving biodiversity in a changing climate. Issues Sci. Technol. 1991-1992: 66-72.

Peterson, A.T. 2001. Predicting species' geographic distributions based on ecological niche modeling. Condor, 103: 599-605.

Peterson, A.T. 2003. Projected climate change effects on Rocky Mountain and Great Plains birds: generalities of biodiversity consequences. Global Change Biol. 9: 647-655.

Peterson, A.T., and Cohoon, K.C. 1999. Sensitivity of distributional prediction algorithms to geographic data completeness. Ecol. Model. 117: 159-164.

Peterson, A.T., and Vieglais, D.A. 2001. Predicting species invasions using ecological niche modeling. Bioscience, 51: 363-371.

Peterson, A.T., Soberon, J., and Sanchez-Cordero, V. 1999. Conservatism of ecological niches in evolutionary time. Science (Wash., D.C.), 285: 1265-1267.

Peterson, A.T., Sanchez-Cordero, V., Soberon, J., Bartley, J., Buddemeier, R.H., and Navarro-Siguenza, A.G. 2001. Effects of global climate change on geographic distributions of Mexican Cracidae. Ecol. Model. 144: 21-30.
Peterson, A.T., Ball, L.G., and Cohoon, K.C. 2002a. Predicting distributions of tropical birds. Ibis, 144: e27-e32.

Peterson, A.T., Ortega-Huerta, M.A., Bartley, J., Sanchez-Cordero, V., Soberon, J., Buddemeier, R.H., and Stockwell, D.R.B. $2002 b$. Future projections for Mexican faunas under global climate change scenarios. Nature (Lond.), 416: 626-629.

Peterson, A.T., Sanchez-Cordero, V., Beard, C.B., and Ramsey, J.M. 2002c. Ecologic niche modeling and potential reservoirs for Chagas disease, Mexico. Emerg. Infect. Dis. 8: 662-667.

Peterson, A.T., Stockwell, D.R.B., and Kluza, D.A. 2002d. Distributional prediction based on ecological niche modeling of primary occurrence data. In Predicting species occurrences: issues of scale and accuracy. Edited by J.M. Scott, P.J. Heglund, and M.L. Morrison. Island Press, Washington, D.C. pp. 617-623.

Pope, V.D., Gallani, M.L., Rowntree, V.J., and Stratton, R.A. 2002. The impact of new physical parametrizations in the Hadley Centre climate model - HadAM3. Hadley Centre for Climate Prediction and Research, Bracknell, Berks, U.K.

Prentice, I.C., and Webb, N.R. 1989. Developing a global vegetation dynamics model: results of an IIASA summer workshop. RR-89-7. International Institute for Applied Systems Analysis, Laxenburg, Austria.

Prentice, I.C., and Webb, T., III. 1998. BIOME 6000: reconstructing global mid-Holocene vegetation patterns from palaeoecological records. J. Biogeogr. 25: 997-1005.

Prentice, I.C., Cramer, W., Harrison, S.P., Leemans, R., Monserud, R.A., and Solomon, A.M. 1992. A global biome model based on plant physiology and dominance, soil properties and climate. J. Biogeogr. 19: 117-134.

Price, J. 2000. Modeling the potential impacts of climate change on the summer distributions of Massachusetts passerines. Bird Observ. 28: 224-230.

Rutherford, M.C., Powrie, L.W., and Schulze, R.E. 2000. Climate change in conservation areas of South Africa and its potential impact on floristic composition: a first assessment. Divers. Distrib. 5: 253-262.

Scachetti-Pereira, R. 2002. Desktop GARP. Available from http:// www.lifemapper.org/desktopgarp/ [accessed 1 February 2003].

Siqueira, M.F.D., and Peterson, A.T. 2003. Global climate change consequences for cerrado tree species. Biota Neotrop. [online], 3(2): 1-14. Available from http://www.biotaneotropica.org.br/ v3n2/pt/abstract?article+BN00803022003 [cited 1 June 2003].

Stockwell, D.R.B. 1999. Genetic algorithms II. In Machine learning methods for ecological applications. Edited by A.H. Fielding. Kluwer Academic Publishers, Boston. pp. 123-144.

Stockwell, D.R.B., and Noble, I.R. 1992. Induction of sets of rules from animal distribution data: a robust and informative method of analysis. Math. Comp. Simul. 33: 385-390.

Stockwell, D.R.B., and Peters, D.P. 1999. The GARP modelling system: problems and solutions to automated spatial prediction. Int. J. Geogr. Inf. Syst. 13: 143-158.

Stockwell, D.R.B., and Peterson, A.T. 2002a. Controlling bias in biodiversity data. In Predicting species occurrences: issues of scale and accuracy. Edited by J.M. Scott, P.J. Heglund, and M.L. Morrison. Island Press, Washington, D.C. pp. 537-546.

Stockwell, D.R.B., and Peterson, A.T. 2002b. Effects of sample size on accuracy of species distribution models. Ecol. Model. 148: $1-13$.

Tian, H., Hall, C., and Qi, Y. 1998. Modeling primary productivity of the terrestrial biosphere in changing environments: toward a dynamic biosphere model. Crit. Rev. Plant Sci. 15: 541-557.

Tian, H., Melillo, J.M., Kicklighter, D.W., McGuire, A.D., Moore, B., III, and Vörösmarty, C.J. 1999. Parameters for global ecosystem models. Nature (Lond.), 399: 536. 
U.S. Geological Survey. 2000. Hydro-1K data set. Available from http://edcdaac.usgs.gov/gtopo30/hydro/ [accessed 1 June 2002].

Visser, M.E., van Noordwijk, A.J., Tinbergen, J.M., and Lessells, C.M. 1998. Warmer springs lead to mistimed reproduction in great tits (Parus major). Proc. R. Soc. Lond. B Biol. Sci. 265: 1867-1870.

Walker, P.A., and Cocks, K.D. 1991. HABITAT: a procedure for modelling a disjoint environmental envelope for a plant or animal species. Global Ecol. Biogeogr. Lett. 1: 108-118.

Walther, G.-R., Post, E., Convey, P., Menzel, A., Parmesan, C., Beebee, T.J.C., Fromentin, J.-M., Hoegh-Guldberg, X.X., and Bairlein, F. 2002. Ecological responses to recent climate change. Nature (Lond.), 416: 389-395. 
Copyright of Canadian Journal of Zoology is the property of NRC Research Press and its content may not be copied or emailed to multiple sites or posted to a listserv without the copyright holder's express written permission. However, users may print, download, or email articles for individual use. 